\title{
A Microsimulation Analysis of Marginal Welfare-Improving Income Tax Reforms for New Zealand*
}

\author{
John Creedy ${ }^{\dagger}$ Norman Gemmell ${ }^{\ddagger}$ Nicolas Hérault ${ }^{\S}$ and Penny Mok ${ }^{\natural}$
}

\begin{abstract}
This paper examines the direction of welfare-improving income tax reforms in the context of New Zealand, which recently reduced its top marginal income tax rate to one of the lowest in the OECD. A behavioural microsimulation model is used, in which social welfare functions are defined in terms of either money metric utility or net income. The model allows for labour supply responses to tax changes, in which a high degree of population heterogeneity is represented along with the details of the highly complex income tax and transfer system. The implications of the results for specific combinations of tax rate or threshold changes, that are both revenue neutral and welfare improving, are explored in detail, recognising the role of distributional value judgements. Results suggest, under a wide range of parameter values and assumptions, that raising the highest income tax rate and/or threshold, would be part of a welfareimproving reform package.
\end{abstract}

JEL Classification: D63; H21; H31; I31; J22.

Keywords: Optimal taxation; tax reform; behavioural microsimulation; social welfare function; money metric utility.

*This paper is part of a larger project on 'Improving New Zealand's Tax Policy via International Tax Transfer Model Benchmarking', funded by an Endeavour Research Grant from the Ministry of Business, Innovation and Employment (MBIE) and awarded to the CPF. Access to the data used in this paper was provided by Statistics New Zealand in accordance with security and confidentiality provisions of the Statistics Act 1975. The results presented in this study are the work of the authors, not Statistics New Zealand. We have benefited from comments by the referees and participants at the Microsimulation Workshop in Wellington, March 2018, and the CPF Public Economics Research Day, Wellington, April 2018.

$\dagger^{\dagger}$ Victoria Business School, Victoria University of Wellington, Wellington, New Zealand.

${ }^{\ddagger}$ Victoria Business School, Victoria University of Wellington, Wellington, New Zealand.

$\S$ Melbourne Institute of Economic and Social Research, University of Melbourne, Australia.

『Ministry of Business, Innovation and Employment (MBIE), Wellington, New Zealand. 


\section{Introduction}

This paper examines tax reforms which improve 'social welfare', where the latter is defined in terms of an explicit social welfare function, defined over either money metric utility or net income. A key objective is to consider the implications of adopting particular value judgements, rather than seeking to make specific policy recommendations. The aim is to examine the direction of changes to the parameters of an existing income tax-transfer system, rather than the properties of an optimal structure. It is argued that helpful practical policy advice regarding the effects of tax changes can be based on a behavioural microsimulation model in which a high degree of population heterogeneity is represented along with the details of complex tax and transfer systems, rather than using the simple forms of standard optimal tax models. Hence, while solving for an optimal tax and transfer system in a microsimulation model is generally impractical, it is possible to identify small changes which can be described as welfare-improving. ${ }^{1}$

The context considered here is the New Zealand income tax structure, and the analysis is carried out using the Treasury's behavioural microsimulation model, TaxWell-B. Like many OECD countries' tax-transfer systems, New Zealand has a multi-rate personal income tax with a progressive rate structure, a comprehensive value added tax ('Goods and Service Tax', GST) and a range of social welfare benefits aimed at lower income and disadvantaged socio-economic groups, such as the disabled, unemployed and sole parents. However, New Zealand's tax system has a number of interesting differences from most other OECD countries. This includes: an income tax with no initial tax-free threshold (the lowest marginal tax rate is 10.5 per cent on income below $\$ 14,000$ ), a relatively low top marginal rate of 33 per cent, a broad-based GST with very few exemptions, and a generous system of familybased refundable tax credits that generates low or negative average income tax rates for a range of households with children in the lower deciles of the income distribution; see Nolan (2017) and Tax Working Group (2018; chapter 5) for more details.

These special characteristics of the New Zealand structure make it an especially interesting context in which to examine the direction of welfare-improving tax reforms using a microsimulation model. It is of interest to consider whether such reforms in New Zealand are similar to Australia, in generally supporting less marginal rate progression (a flattening

\footnotetext{
${ }^{1}$ On microsimulation modelling, see Creedy and Kalb (2005, 2006). Examples are in Decoster and Haan (2015), Dagsvik et al. (2014), Thoresen (2004) Thoresen and Vattø (2015) and Capéau et al. (2016). When using such models it is nevertheless important to be aware of their limitations. In particular, they deal only with the supply side of the labour market and, despite modelling labour supply, have no genuine dynamic element. Furthermore, they deal only with financial incentive effects rather than administrative behaviour and monitoring features designed to reduce moral hazard.
} 
of the rate structure), or whether New Zealand's relatively low top rate implies marginal reforms producing more rate progression. ${ }^{2}$

The modelling approach adopted here initially examines small changes in individual marginal tax rates and income thresholds in the income tax schedule, allowing for changes that are both revenue neutral and welfare improving to be explored, and highlighting the role of value judgements. This involves the computation of social welfare changes per dollar of revenue, for changes in each existing marginal income tax rate, using explicit forms of the social welfare function. Then the range of possible tax reforms considers welfareimproving combinations of tax rate and threshold changes. The results show that there is some scope for marginal tax reforms in New Zealand that are both revenue neutral and welfare improving, depending on the distributional value judgements adopted.

The microsimulation methods used are discussed in Section 2. This is complicated by the existence of highly nonlinear budget constraints facing individuals, which affect the computation of welfare changes and also leads to an asymmetry in the effects of tax rate increases and decreases. Section 3 presents aggregate results relating to reforms to the New Zealand income tax structure. Changes to the income tax rates are examined in Section 4, while changes to income thresholds, as well as combined tax rate and threshold changes, are discussed in Section 5. Brief conclusions are in Section 6.

\section{The Modelling Approach}

This section describes the approach used to obtain results. First, the behavioural simulation model, TaxWell-B, is outlined in Subsection 2.1, and the simulation method is described in more detail in Subsection 2.2. In examining welfare improvements, value judgements concern three aspects: the welfare metric; the form of the social welfare function to be used and; the definition of the unit of analysis. The reported results are based on the use of money metric utility per adult equivalent, using parametric adult equivalence scales. Subsection 2.3 explains how welfare changes, money metric utility and the equivalence scales are computed. The choice of welfare function, discussed in subsection 2.4, is closely related to value judgements regarding inequality: different values of inequality aversion are used. The simulation results are based on the New Zealand tax and transfer system for the financial year of 2011/12. Subsection 2.5 gives the details of the 2011/12 tax structure in

\footnotetext{
${ }^{2}$ Examining the direction of welfare-improving reforms in Australia using the MITTS behavioural microsimulation model, Creedy and Hérault (2012) report that, for a range of social welfare assumptions, a welfare-improving reform involves a reduction in the top marginal rate, which was around 47 per cent (in 2003/04).
} 
New Zealand.

\section{$2.1 \quad$ TaxWell-B}

The New Zealand behavioural microsimulation model, TaxWell-B, requires, for each individual in the database, net incomes for a range of hours worked before and after a tax and transfer change. These are obtained using the arithmetic model, TaxWell-A, containing the details of the social security and personal tax system. Both models utilise the Household Economic Survey, a cross-sectional survey collected by Statistics New Zealand. This records, for each individual, income from current jobs and other non-wage income such as interest and dividends. Population values are obtained by using the sample weights.

Given information about an individual's wage rate and a wide range of characteristics, net income is determined for each of a range of discrete hours levels. For those not working at the time of the survey, a wage rate is imputed, based on econometric estimates of wage functions for a range of demographic groups. Wage equations were estimated separately for married men, married women, single men, single women and sole parents using pooled HES data from 2006/07 to 2010/11. Preference functions were estimated jointly for married men and women, and separately for single men, single women and sole parents; see Mercante and Mok (2014a, 2014b).

Single men and women, sole parents and married women have working hours choices of $0,5,10,15,20,25,30,35,40,45$ and 50 hours of work. Married men have hours choices of 0 , 10, 20, 30, 40 and 50 hours of work. Hence, couples have a total of 66 working-hour choices. For couples, the female hours distribution therefore covers a wider range of part-time and full-time hours than the male distribution.

In calculating net incomes, Taxwell-A assumes a take-up rate for welfare benefits and tax credits of 100 per cent, for both tax systems examined. This may lead to some overestimation of expenditure on the different payments in both pre- and post-reform. The simulated changes reported here are not expected to be biased as the policy changes did not expand eligibility to a large extent. All persons for whom labour supply is modelled, except sole parents, are potentially eligible for Unemployment Benefits. Sole parents are eligible for Domestic Purpose Benefit. The income-test rules are then applied to calculate actual benefit levels. The simulations presented below are based on the tax and transfer structure of New Zealand for the financial year $2011 / 12 .^{3}$

\footnotetext{
${ }^{3}$ Certain groups are not included in the labour supply analysis, and in simulations their hours and gross incomes are held fixed. These include full-time students, disabled, retired and self-employed.
} 


\subsection{The Simulation Method}

In TaxWell-B, labour supply is based on a structural approach where individuals are assumed to be able to work at only a number of discrete hours levels, rather than being able to vary hours continuously. Individuals choose a combination of leisure and income to maximise utility. Preferences have a deterministic component which is quadratic in work hours and net income, and parameters vary depending on a range of characteristics. For couples, both partners simultaneously determine labour supply, by maximising a single utility function on the assumption that partners pool their incomes. A random utility component, from a Type-I extreme-value distribution, is added to the deterministic component, to capture unobserved preference heterogeneity.

This means that the model does not produce a single deterministic hours level for each individual following a change to the tax and transfer system. Each discrete hours level is associated with a probability for each person. The discrete hours approach has substantial advantages over the continuous hours model, in allowing the full details of the tax structure to be modelled and overcoming the endogeneity problem that would otherwise be raised by the fact that both the hours worked and the marginal tax rate faced are jointly determined when there are piecewise linear budget constraints.

The simulation procedure for each individual or couple begins by converting the observed working hours to the closest discrete level. Then, given the parameter estimates of the preference functions (which allow for observed heterogeneity), the deterministic components of utility for each hours level are calculated for the net incomes generated by the pre-reform tax and transfer system. A set of random draws, one for each discrete hours level, is then taken from the Type-I extreme value distribution. For each hours level, the total value of utility is determined by adding a random draw to the deterministic component of utility. The hours level giving maximum total utility can then be obtained for that set of random draws.

The sets for which observed hours are equal to optimum hours in the pre-reform situation are used to determine the conditional distribution of optimal hours levels after the reform for each individual: appropriate sets of draws are obtained using the method proposed by Bourguignon et al. (2001). To obtain sufficient information regarding the post-reform hours distribution over the discrete hours levels for each individual, 100 such sets of draws are used in the simulations. For the post-reform analysis, the new net incomes cause the deterministic component of utility at each hours level to change. Using the 100 sets of draws retained for each individual from the calibration procedure, a distribution of optimal hours of work is determined. This is essentially a conditional probability distribution over 
the set of discrete hours for each individual under the post-reform policy. For a detailed introduction to discrete hours modelling and the calibration approach in microsimulation, see Creedy and Kalb (2005).

\subsection{Computation of the Welfare Metric}

An important modelling requirement is to specify a suitable welfare metric and social welfare function. In the basic optimal tax model, this is straightforward given the choice of cardinalisation of utility, where common preferences and homothetic utility functions are usually assumed. ${ }^{4}$ The conditions required for welfare functions to possess basic properties turn out to be highly restrictive: see, for example, Donaldson (1992) and Blackorby, Laisney and Schmachtenberg (1993). ${ }^{5}$

Further complications are raised by differences between individuals in their preference for leisure: it is known that with preference heterogeneity, standard welfare functions based on money metric utility can violate certain conditions, such as the principle of transfers. One approach was suggested by Aaberge and Colombino (2008) and Ericson and Flood (2009), who used a discrete hours structural approach to model labour supply, allowing for a substantial amount of population heterogeneity. However, the welfare metric used in their social welfare function is a value of utility based on an independently estimated utility function, which is considered to be the same for all individuals. ${ }^{6}$

While recognising the potential difficulty, the approach used here is to retain preference heterogeneity when producing money metric utility. The latter requires an assumption about the 'reference prices' to be used, and in the present case these are taken to be the pre-reform net wage rates. This is of course one particular - and very convenient - cardinalisation of the utility function, and other possibilities are obviously available. For a thorough analysis of issues and alternative approaches, see Decoster and Haan (2015), which extends the earlier treatment by Preston and Walker (1999).

Starting from the actual tax structure, and considering small changes in a range of tax parameters, the microsimulation model is used to obtain values of welfare and revenue

\footnotetext{
${ }^{4}$ Optimal income tax models maximise a social welfare function, subject to a government budget constraint. The partial equilibrium environment usually consists of individuals with identical preferences but different abilities (reflected in exogenous wage rates), and the welfare function is specified as a variant of the basic utilitarian form, allowing for inequality aversion. The welfare metric is thus utility, which is necessarily considered to be cardinal and interpersonally comparable.

${ }^{5}$ Even a minimum requirement of homotheticity is not satisfied by the types of direct utility function used in practical labour supply analyses. This has led to the adoption of non-welfarist approaches, such as that proposed by Fleurbaey and Maniquet (1999).

${ }^{6}$ Blundell and Shephard (2009) simply adopt a social welfare function based on a common (isoelastic) utility transformation.
} 
changes, denoted $\Delta W$ and $\Delta R$ respectively, for each tax parameter in turn. In an optimal system, the ratio, $\Delta W / \Delta R$, should be similar for changes in all tax parameters. Hence, the direction of a marginal welfare-improving reform is indicated by relative orders of magnitude of all the $\Delta W / \Delta R$ ratios. The broad approach follows that pioneered by Ahmad and Stern (1984), when considering marginal indirect tax reforms. However, unlike their context where computations rely upon estimates of demand elasticities, the present approach uses the microsimulation model to compute the labour supply, tax revenue, and welfare changes for each individual, resulting from 'small' tax changes. ${ }^{7}$

In view of the asymmetry of responses to increases and decreases in tax rates and thresholds, it is necessary to consider the full range of tax parameter changes in both directions. As explained in Subsection 2.2, the behavioural simulations produce a frequency distribution of post-reform hours for each individual, conditional on the individual's optimal pre-reform hours being equal to observed discretised hours. Similarly a frequency distribution of welfare and net income changes is obtained for each individual. The approach has the advantage of ensuring consistency between the welfare evaluations and the estimated labour supply responses.

Although the measurement of welfare changes is relatively straightforward in deterministic utility models with linear budget constraints, there does not appear to be complete consensus in the present context. The welfare changes in the random utility model with discrete hours are obtained here using the following method, which is examined in detail by Creedy, Hérault and Kalb (2011). A derivation of the precise distribution in the random utility model is given by Dagsvik and Karlström (2005), though their derivation is not readily implemented. The present approach is much easier to implement, as most of the information is already available from a tax reform simulation: only quadratic equations need to be solved. ${ }^{8}$

Hours level, $h_{i}$, gives rise to net income of $c_{i, T_{k}}$ under tax structure, $T_{k}$. Utility is equal to a deterministic component, $U\left(c_{i, T_{k}}, h_{i}\right)$, plus a random component, $v_{i}$, so that total utility is:

$$
U_{i, T_{k}}=U\left(c_{i, T_{k}}, h_{i}\right)+v_{i}
$$

Suppose there are two discrete hours levels, and consider a single set of random utility draws, $v_{1}$ and $v_{2}$. With tax structure 0 , hours level 2 is chosen if $U\left(c_{2, T_{0}}, h_{2}\right)+v_{2}>U\left(c_{1, T_{0}}, h_{1}\right)+v_{1}$. Suppose the tax structure changes to structure 1. For this set of draws, conditional on hours

\footnotetext{
${ }^{7}$ Any analysis of marginal reforms must recognise the possibility that there may be multiple local optima, despite the fact that standard optimal tax models (which reflect very little heterogeneity) produce a single optimal structure.

${ }^{8}$ For an early treatment of welfare changes in discrete models, see Hanemann (1983).
} 
level 2 being chosen under the initial tax structure, the compensating variation is the smaller of two values of $C V$, obtained by solving each of the following two equations:

$$
U\left(c_{2, T_{1}}+C V_{2}, h_{2}\right)+v_{2}=U\left(c_{2, T_{0}}, h_{2}\right)+v_{2}
$$

and:

$$
U\left(c_{1, T_{1}}+C V_{1}, h_{1}\right)+v_{1}=U\left(c_{2, T_{0}}, h_{2}\right)+v_{2}
$$

If, under the initial tax structure, hours level 1 had been chosen instead of level 2, the righthand sides of $(2)$ and $(3)$ are replaced by $U\left(c_{1, T_{0}}, h_{1}\right)+v_{1}$. This approach ensures that (for the given set of random draws, $v_{1}$ and $v_{2}$ ) the compensating variation actually ensures that the individual, faced with the discrete hours options available, can achieve 'compensation'; that is, the welfare after compensation is the same as pre-change welfare.

The random utility framework means that, unlike the deterministic case, it is not possible to discuss changes simply in terms of moving along a given indifference curve. Even if only the deterministic component of utility were considered, the discrete hours framework means that simple linearisation of a budget constraint (based on the slope of an indifference curve at a 'corner' of the budget set) may not result in a feasible compensation.

Consider equation (2). The term, $U\left(c_{2, T_{0}}, h_{2}\right)+v_{2}$, has of course been calculated during calibration. The standard expression for the root of a quadratic can then be used to compute $c_{2, T_{1}}+C V_{2}$, and since $c_{2, T_{1}}$ has already been computed, $C V_{2}$ can easily be obtained. Similarly for equation (3), where $c_{1, T_{1}}+C V_{1}$ is obtained as the solution to a quadratic and $c_{1, T_{1}}$ is subtracted to get $C V_{1}$. The appropriate $C V$ is the minimum of these two values.

In general, where there are $H$ hours levels, suppose that (discretised) level, $h_{m}$ is chosen in the base tax structure, 0 . After the shift to tax structure 1, calculate the $H$ values of $C V_{j}$, where:

$$
U\left(c_{j, T_{1}}+C V_{j}, h_{j}\right)+v_{j}=U\left(c_{m, T_{0}}, h_{m}\right)+v_{m}
$$

and the $C V$ is given by $\min \left(C V_{1}, \ldots, C V_{H}\right)$. This is repeated for all sets of draws. In the case of the equivalent variation, equation (4) is replaced by:

$$
U\left(c_{j, T_{0}}-E V_{j}, h_{j}\right)+v_{j}=U\left(c_{m, T_{1}}, h_{m}\right)+v_{m}
$$

and $E V$ is given by $\max \left(E V_{1}, \ldots, E V_{H}\right)$. In each case, after solving for $c_{j, T_{0}}-E V_{j}$, using the appropriate root of a quadratic, this is deducted from the value of $c_{j, T_{0}}$, to obtain the required $E V_{j}$. Hence, the equivalent variation from a tax policy change, $E V$, is obtained by searching all discrete labour supply points for each conditional draw, while taking into account the non-linearity and non-convexity of the budget constraint. 
The steps in the social evaluation are as follows. For each income unit, the initial money metric utility, $M_{0}$, is obtained, using pre-reform taxes as 'reference prices'. This is equal to 'full income' under the pre-reform system, defined as the net income which could be obtained if all the endowment of time were devoted to work at the going wage rate. For each individual, the net income at 80 hours of work (the assumed 'endowment' of work hours per week) by all adult members of the income unit under pre-reform taxes is calculated, giving full income for the unit. Then, given the equivalent variation resulting from the reform for each of the discrete hours levels, as calculated above, money metric utility is computed as $M_{1}=M_{0}-E V$. A distribution of $E V \mathrm{~s}$ and thus money metric utilities is obtained for each unit over the 100 sets of draws used in calibration.

For each income unit, the adult equivalent size, $s$, is computed, following Banks and Johnson (1994) and Jenkins and Cowell (1994), using the following parametric scales:

$$
s=\left(n_{a}+\theta n_{c}\right)^{\alpha}
$$

where $n_{a}$ and $n_{c}$ are respectively the number of adults and children in the unit, $\theta$ is the weight attached to children and $\alpha$ represents the extent of economies of scale. The size of each unit, $i, s_{i}$, is used to compute money metric utility per adult equivalent person, $m_{i}$.

\subsection{The Social Welfare Function}

In computing inequality and welfare measures with the individual as the unit of analysis, each value of $m_{i}$ is weighted by the actual number of persons in the income unit, $n_{i}$. This paper uses Atkinson's inequality measure, $A(\varepsilon)$, where $\varepsilon$ is the degree of relative inequality aversion. The inequality measure is the proportional difference between the arithmetic mean, $\bar{y}$, and the equally distributed equivalent value, $y_{e d e}$, where the latter is the value which, if obtained by everyone, gives the same social welfare as the actual distribution; hence $A(\varepsilon)=1-y_{\text {ede }} / \bar{y}$. Using an additive welfare function based on constant relative inequality aversion, $\varepsilon$, of the form:

$$
W=\frac{1}{1-\varepsilon}\left(\frac{1}{n} \sum_{i=1}^{n} y_{i}^{1-\varepsilon}\right)
$$

the equally distributed equivalent value, $y_{e d e}$, is in general, for a set of values $y_{i}$, for $i=$ $1, \ldots, n$, equal to $\left(\frac{1}{n} \sum_{i=1}^{n} y_{i}^{1-\varepsilon}\right)^{1 /(1-\varepsilon)}$.

Results can be obtained for a range of inequality aversion parameters, $\varepsilon$. Finally, social welfare in each system is most conveniently obtained using the abbreviated form of the 
welfare function in $(7)$, given by: ${ }^{9}$

$$
\widetilde{W}=\bar{y}(1-A(\varepsilon))
$$

where $\bar{y}$ is the arithmetic mean value of the money metric utility per adult equivalent. The use of the abbreviated form, showing the trade-off between 'equity and efficiency', is convenient because it ensures that $\widetilde{W}$ is positive for all values of $\varepsilon$.

Table 1: The Pseudo Distribution Method: Two Persons and Two Hours Levels

\begin{tabular}{lccccc}
\hline Combination & \multicolumn{2}{c}{ Incomes } & Probabilies & \multicolumn{2}{c}{ The pseudo distribution } \\
& $\mathrm{A}$ & $\mathrm{B}$ & (post reform) & Incomes & Probabilities \\
\hline 1 & $w_{A} h_{1}$ & $w_{B} h_{1}$ & $p_{1}=\left(p_{1, A}\right)\left(p_{1, B}\right)$ & $w_{A} h_{1}$ & $\left(p_{1}+p_{3}\right) / 2$ \\
2 & $w_{A} h_{2}$ & $w_{B} h_{1}$ & $p_{2}=\left(p_{2, A}\right)\left(p_{1, B}\right)$ & $w_{B} h_{1}$ & $\left(p_{1}+p_{2}\right) / 2$ \\
3 & $w_{A} h_{1}$ & $w_{B} h_{2}$ & $p_{3}=\left(p_{1, A}\right)\left(p_{2, B}\right)$ & $w_{A} h_{2}$ & $\left(p_{2}+p_{4}\right) / 2$ \\
4 & $w_{A} h_{2}$ & $w_{B} h_{2}$ & $p_{4}=\left(p_{2, A}\right)\left(p_{2, B}\right)$ & $w_{B} h_{2}$ & $\left(p_{3}+p_{4}\right) / 2$ \\
\hline
\end{tabular}

In producing the summary measures of the various distributions, it is necessary to deal with the fact that each individual has a post-reform hours distribution. A simple approach of using the arithmetic mean values for each person would produce a poor approximation. Instead, the 'pseudo distribution' approach of Creedy, Kalb and Scutella (2006) is used. This can be described using a simple example involving two individuals, A and B, and two discrete hours levels $h_{1}$ and $h_{2}$, where the individuals face wage rates, $w_{A}$ and $w_{B}$, respectively. The post-reform probabilities associated with the two hours levels are $p_{1, A}$ and $p_{2, A}$ and $p_{1, B}$ and $p_{2, B}$. The four alternative possible combinations of incomes are shown in the second and third columns of Table 1. On the assumptions that the choices of individuals are independent, the probabilities associated with these combinations are given in column four. The resulting pseudo distribution is shown in the final two columns. The possible income levels are in the penultimate column, and of course these are not necessarily in rank order here. The probabilities associated with each of these incomes are shown in the final column: it is easily confirmed that these add to 1 . This pseudo distribution approach contrasts with a the simple use of average income for each individual, which would give just two post-reform income levels of $w_{A}\left(p_{1, A} h_{1}+p_{2, A} h_{2}\right)$ and $w_{B}\left(p_{1, B} h_{1}+p_{2, B} h_{2}\right)$.

When comparing the Atkinson inequality values, the question arises of what range of values should be considered when examining the sensitivity of results to $\varepsilon$. In the analysis below, results are reported for values ranging from 0.1 to 1.4. These orders of magnitude can be interpreted by considering the 'leaky bucket' experiment of making a transfer from a

\footnotetext{
${ }^{9}$ On abbreviated forms see, for example, Lambert (1993).
} 
richer to a poorer person. A transfer from person 2 to person 1, in the context of incomes, $y_{2}>y_{1}$, which leaves social welfare unchanged is given by:

$$
\left.\frac{d y_{1}}{d y_{2}}\right|_{W}=-\left(\frac{y_{2}}{y_{1}}\right)^{-\varepsilon}
$$

Hence if, for discrete changes and a transfer of 1 from the richest person, $\Delta y_{2}=-1$, and if incomes are such that $y_{2}=2 y_{1}$, then the amount which must be given to the poorest person is $\Delta y_{1}=2^{-\varepsilon}$. For example, if $\varepsilon=0.1$, a leak of 7 cents is tolerated from the dollar taken from person 2, so that person 1 receives 93 cents. For $\varepsilon=0.2$, the leak increases to 13 cents. A value of $\varepsilon$ of 1.4 may thus be considered high, since $\Delta y_{1}=0.39$ and the judge is prepared to lose 61 cents from the dollar. ${ }^{10}$

\subsection{The New Zealand Income Tax Structure}

The income tax structure is given in Table 2 , where $t_{i}$ is the marginal rate applied above an annual income of $a_{i}$, for $i=1, \ldots, 4$. Consider taking $\$ 1$ from someone in the top tax bracket with $\$ 100 \mathrm{k}$, and making a transfer to someone in the bottom tax bracket with $\$ 10 \mathrm{k}$, so that $y_{2} / y_{1}=10$, For values of $\varepsilon$ of $0.1,0.2,0.8$ and 1.4 , the leaks that would be tolerated are respectively 20,37, 84 and 96 cents. The higher value of $\varepsilon$ therefore approaches 'extreme' inequality aversion, where the 'judge' is willing simply to confiscate income from the richest person. ${ }^{11}$ If the $\$ 1$ taken from the person with $\$ 100 \mathrm{k}$ is used to make a transfer to someone in the second tax bracket with, say, $\$ 25 \mathrm{k}$, the leaks tolerated for the same values of $\varepsilon$ are respectively 13, 24, 67 and 86 cents.

A distinguishing feature of the New Zealand income tax is that there is no tax-free income range, so that the first rate of 10.5 per cent applies from the first dollar, although various rebates also apply. The marginal income tax rates, particularly in the lower-income ranges, do not reflect effective marginal tax rates in view of the existence of a range of means-tested benefits with various taper or abatement rates. The present approach can also be used to examine small changes in benefit levels and associated abatement rates though that is not pursued here.

The simulations reported are for small tax changes, such that each of the marginal rates was in turn decreased by one percentage point, and then increased by one percentage point, and the resulting changes in total revenue and social welfare were obtained. The

\footnotetext{
${ }^{10}$ The tolerance for leaks clearly depends on the assumed ratio of incomes of transferor and transferee. For example, if $y_{2} / y_{1}=3$, then when $\varepsilon=0.1, \Delta y_{1}=0.90$ and a leak of 10 cents is tolerated, and if $\varepsilon=0.2$, $\Delta y_{1}=0.80$ and the maximum leak tolerated is 20 cents. Some surveys have found an average inequality aversion in the context of the Atkinson inequality measure of about 0.2; see Amiel, Creedy and Hurn (1999).

${ }^{11}$ Indeed, with $\varepsilon=3$, the leak tolerated is 99.9 cents, virtually the whole of the $\$ 1$ taken from person 2 .
} 
Table 2: The New Zealand Income Tax Structure: 2011/2012

\begin{tabular}{llc}
\hline No. & Income threshold (in NZ $\$$ ) & Marginal tax rate (per cent) \\
\hline 1 & $a_{1}=0$ & $t_{1}=10.5$ \\
2 & $a_{2}=14,000$ & $t_{2}=17.5$ \\
3 & $a_{3}=48,000$ & $t_{3}=30.0$ \\
4 & $a_{4}=70,000$ & $t_{4}=33.0$ \\
\hline
\end{tabular}

use of small changes means that the labour supply adjustments are expected to be quite small, given the use of a discrete hours approach. Furthermore, it is widely recognised that labour supply responses result from both income and substitution effects: for example, 'full income' falls when a marginal tax rate increases, but the effective price of leisure also falls. Hence, labour supply responses cannot always be known a priori, and are likely to vary substantially among individuals, in view of the considerable heterogeneity in preferences and other characteristics.

\section{Aggregate Effects}

Tables 3 and 4 report aggregate effects for, respectively, increases and decreases in each marginal tax rate by one percentage point. Tables 5 and 6 report results for increases and decreases in thresholds by $\$ 1000$. These are obtained by adding all expected $E V$ and net incomes across all income units without equivalising the amounts. All monetary values are in millions of dollars per year. Values in the tables are given to two decimal places, but in computing all changes, more decimal places were of course used. The threshold changes are for $a_{2}, a_{3}$ and $a_{4}$ only, as $a_{1}=0$.

Changes in net government revenue account both for changes in income tax revenue and for consequent changes in expenditures on social security. Indeed, government spending on pensions, allowances and rebates is affected by changes in income taxes and labour supply. The tables also present labour supply responses by demographic group. For couples, the first amount relates to the male partner while the second amount is for the female partner. The marginal excess burden, $M E B$, is equal to $E V-M R$, where $M R$ is the actual change in net revenue. The marginal welfare cost is the marginal excess burden per dollar of extra revenue, $M E B / M R$. Following the convention used in the public finance literature, equivalent variations, and hence marginal welfare costs, are defined such that they are positive for tax increases and welfare losses.

Examination of Table 3 shows that, in nearly all cases, an increase in a marginal tax rate produces net revenue increases that are smaller when adverse labour supply effects 
are modelled. However, for sole parents, an increase in the 4 th tax rate increases revenue but leaves average hours unchanged. Nevertheless, some individual labour supply increases (where income effects dominate for some of these higher-income individuals) imply that allowing for labour supply changes, aggregate net revenue increases by more than when labour supply is fixed. For increases in other marginal tax rates, average hours of sole parents fall and net revenue increases by less than it does under an assumption of fixed labour supply.

From Table 4, reductions in marginal tax rates generally reduce revenue, though the resulting increase in average hours worked means that the reductions are lower than if labour supply is held fixed. Again an exception applies to sole parents. For this group, the reduction in the first tax rate produces a net revenue increases. This result stems from the fact that the increase in labour supply raises taxable income and reduces welfare payments sufficiently to compensate for the lower tax rate. In this case, the group of sole parents facing the lowest income tax rate may be said to be on the 'wrong side' of the respective Laffer curve.

This type of response means that, for an increase in $t_{4}$ and a reduction in $t_{1}$, for sole parents the excess burden concept is not appropriate. This is because the change in revenue in absolute terms is more than the change in welfare, measured by the $E V$. Sole parents also provide the only exception where threshold changes are involved: these are for an increase in $a_{2}$ and a reduction in $a_{4}$, which involve relatively large labour supply responses. ${ }^{12}$

The results also show that the small labour supply effects are nevertheless associated with substantial marginal welfare costs, ranging from around 7 to 14 per cent for the various 1 percentage point or $\$ 1,000$ tax reforms considered. This serves to highlight the empirical importance here of the known theoretical result that small observed net labour supply effects on average are consistent with substantial marginal excess burdens associated with tax changes. This important result arises because a small Marshallian elasticity can be associated with a relatively large Hicksian elasticity (determined by the convexity of indifference curves); see Creedy et al. (2006), Creedy and Mok (2018).

The tables also allow evaluation of the effects on welfare of tax-induced changes in leisure, as distinct from effects on net incomes. For tax increases, reductions in welfare as measured by changes in aggregate $E V$ are smaller than reductions in household income because welfare measures account for the increase in leisure and home production time, following the decrease in labour supply. Similarly, changes in welfare are smaller than changes in net income for tax reductions because welfare measures value the decrease in

\footnotetext{
${ }^{12}$ This kind of situation is discussed further in the New Zealand context by Creedy and Mok (2018).
} 
Table 3: Marginal Tax Rate Increases of One Percentage Point: Money Values in Millions

\begin{tabular}{|c|c|c|c|c|c|}
\hline & Couples & $\begin{array}{l}\text { Single } \\
\text { men }\end{array}$ & $\begin{array}{l}\text { Single } \\
\text { women }\end{array}$ & $\begin{array}{l}\text { Sole } \\
\text { parents }\end{array}$ & Total \\
\hline \multicolumn{6}{|l|}{ Increase in 1 st tax rate } \\
\hline Net government revenue change (LS fixed) & 236.03 & 50.52 & 50.73 & 7.27 & 344.55 \\
\hline Net government revenue change (incl. LS) & 218.39 & 49.43 & 39.17 & 2.20 & 309.19 \\
\hline Average hours change in hours per week & $-0.02,-0.02$ & 0.00 & -0.05 & -0.05 & -0.02 \\
\hline Equivalent variation & 235.96 & 50.51 & 50.68 & 7.25 & 344.40 \\
\hline Marginal Welfare Cost & 0.08 & 0.02 & 0.29 & 2.30 & 0.11 \\
\hline Aggregate net income change & -259.24 & -51.62 & -57.58 & -9.88 & -378.33 \\
\hline Diff b/w net income change and EV (\%) & 8.98 & 2.15 & 12.00 & 26.59 & 8.97 \\
\hline \multicolumn{6}{|l|}{ Increase in 2 nd tax rate } \\
\hline Net government revenue change (LS fixed) & 370.88 & 72.55 & 61.89 & 15.10 & 520.42 \\
\hline Net government revenue change (incl. LS) & 334.42 & 70.61 & 45.23 & 4.40 & 454.66 \\
\hline Average hours change in hours per week & $-0.03,-0.05$ & -0.01 & -0.09 & -0.12 & -0.05 \\
\hline Equivalent variation & 370.61 & 72.53 & 61.78 & 15.04 & 519.96 \\
\hline Marginal Welfare Cost & 0.11 & 0.03 & 0.37 & 2.42 & 0.14 \\
\hline Aggregate net income change & -425.75 & -74.97 & -78.80 & -22.83 & -602.35 \\
\hline Diff b/w net income change and EV (\%) & 12.95 & 3.25 & 21.61 & 34.14 & 13.68 \\
\hline \multicolumn{6}{|l|}{ Increase in 3 rd tax rate } \\
\hline Net government revenue change (LS fixed) & 108.96 & 15.15 & 12.19 & 3.04 & 139.33 \\
\hline Net government revenue change (incl. LS) & 98.39 & 14.13 & 10.52 & 1.95 & 124.98 \\
\hline Average hours change in hours per week & $-0.01,-0.01$ & 0.00 & -0.01 & -0.01 & -0.01 \\
\hline Equivalent variation & 108.89 & 15.15 & 12.17 & 3.03 & 139.24 \\
\hline Marginal Welfare Cost & 0.11 & 0.07 & 0.16 & 0.55 & 0.11 \\
\hline Aggregate net income change & -123.97 & -16.95 & -15.31 & -3.30 & -159.53 \\
\hline Diff b/w net income change and EV (\%) & 12.17 & 10.62 & 20.51 & 8.13 & 12.72 \\
\hline \multicolumn{6}{|l|}{ Increase in 4 th tax rate } \\
\hline Net government revenue change (LS fixed) & 132.53 & 26.33 & 10.82 & 2.77 & 172.45 \\
\hline Net government revenue change (incl. LS) & 123.50 & 25.38 & 8.81 & 3.20 & 160.89 \\
\hline Average hours change in hours per week & $-0.01,0.00$ & 0.00 & -0.01 & 0.00 & 0.00 \\
\hline Equivalent variation & 132.42 & 26.32 & 10.80 & 2.77 & 172.31 \\
\hline Marginal Welfare Cost & 0.07 & 0.04 & 0.23 & -0.14 & 0.07 \\
\hline Aggregate net income change & -142.92 & -28.09 & -14.54 & -1.80 & -187.35 \\
\hline Diff b/w net income change and EV (\%) & 7.34 & 6.30 & 25.70 & -53.42 & 8.03 \\
\hline
\end{tabular}

Note: The first 2 rows show the change in tax revenue net of changes in social transfer payments (in millions) with labour supply held fixed (row 1) and allowed to vary (row 2). Row 3 shows mean hours changes in labour supply: for couples, the first amount relates to the male partner while the second amount is for the female partner. Rows 4 and 5 report the equivalent variation (EV) and marginal welfare cost. Changes in aggregate net (after tax and transfers) incomes are shown in row 6, in millions, for the variable labour supply case. Row 7 gives the percentage difference between the EV and net income change. 
Table 4: Marginal Tax Rate Reductions of One Percentage Point: Money Values in Millions

\begin{tabular}{|c|c|c|c|c|c|}
\hline & Couples & $\begin{array}{r}\text { Single } \\
\text { men }\end{array}$ & $\begin{array}{r}\text { Single } \\
\text { women }\end{array}$ & $\begin{array}{r}\text { Sole } \\
\text { parents }\end{array}$ & Total \\
\hline \multicolumn{6}{|l|}{ Decrease in 1 st tax rate } \\
\hline Net government revenue change (LS fixed) & -236.05 & -50.55 & -50.76 & -7.29 & -344.65 \\
\hline Net government revenue change (incl. LS) & -226.33 & -49.34 & -42.38 & 0.17 & -317.88 \\
\hline Average hours change in hours per week & $0.01,0.02$ & 0.01 & 0.05 & 0.10 & 0.02 \\
\hline Equivalent variation & -236.10 & -50.55 & -50.79 & -7.33 & -344.76 \\
\hline Marginal Welfare Cost & -0.04 & -0.02 & -0.20 & - & -0.08 \\
\hline Aggregate net income change & 255.42 & 51.96 & 55.77 & 12.05 & 375.20 \\
\hline Diff b/w net income change and EV (\%) & 7.57 & 2.72 & 8.92 & 39.17 & 8.11 \\
\hline \multicolumn{6}{|l|}{ Decrease in 2 nd tax rate } \\
\hline Net government revenue change (LS fixed) & -370.88 & -72.55 & -61.89 & -15.10 & -520.42 \\
\hline Net government revenue change (incl. LS) & -348.46 & -68.99 & -50.84 & -3.40 & -471.68 \\
\hline Average hours change in hours per week & $0.02,0.05$ & 0.02 & 0.08 & 0.18 & 0.05 \\
\hline Equivalent variation & -371.03 & -72.55 & -61.94 & -15.18 & -520.71 \\
\hline Marginal Welfare Cost & -0.06 & -0.05 & -0.22 & -3.47 & -0.10 \\
\hline Aggregate net income change & 418.54 & 77.73 & 76.92 & 25.38 & 598.56 \\
\hline Diff b/w net income change and EV (\%) & 11.35 & 6.66 & 19.47 & 40.18 & 13.01 \\
\hline \multicolumn{6}{|l|}{ Decrease in $3 r d$ tax rate } \\
\hline Net government revenue change (LS fixed) & -108.96 & -15.15 & -12.19 & -3.04 & -139.33 \\
\hline Net government revenue change (incl. LS) & -105.55 & -14.46 & -11.04 & -1.88 & -132.92 \\
\hline Average hours change in hours per week & $0.00,0.00$ & 0.00 & 0.01 & 0.01 & 0.00 \\
\hline Equivalent variation & -108.98 & -15.15 & -12.20 & -3.04 & -139.37 \\
\hline Marginal Welfare Cost & -0.03 & -0.05 & -0.11 & -0.62 & -0.05 \\
\hline Aggregate net income change & 115.69 & 16.40 & 15.32 & 4.00 & 151.41 \\
\hline Diff b/w net income change and EV (\%) & 5.80 & 7.63 & 20.39 & 23.86 & 7.95 \\
\hline \multicolumn{6}{|l|}{ Decrease in 4 th tax rate } \\
\hline Net government revenue change (LS fixed) & -132.53 & -26.33 & -10.82 & -2.77 & -172.45 \\
\hline Net government revenue change (incl. LS) & -121.10 & -25.59 & -9.49 & -2.11 & -158.30 \\
\hline Average hours change in hours per week & $0.01,0.00$ & 0.00 & 0.00 & 0.01 & 0.00 \\
\hline Equivalent variation & -132.63 & -26.34 & -10.82 & -2.77 & -172.56 \\
\hline Marginal Welfare Cost & -0.10 & -0.03 & -0.14 & -0.31 & -0.09 \\
\hline Aggregate net income change & 154.70 & 27.91 & 13.45 & 3.73 & 199.79 \\
\hline Diff b/w net income change and EV (\%) & 14.26 & 5.64 & 19.55 & 25.80 & 13.63 \\
\hline
\end{tabular}

Note: The first 2 rows show the change in tax revenue net of changes in social transfer payments (in millions) with labour supply held fixed (row 1) and allowed to vary (row 2). Row 3 shows mean hours changes in labour supply: for couples, the first amount relates to the male partner while the second amount is for the female partner. Rows 4 and 5 report the equivalent variation (EV) and marginal welfare cost. Changes in aggregate net (after tax and transfers) incomes are shown in row 6, in millions, for the variable labour supply case. Row 7 gives the percentage difference between the EV and net income change. 
Table 5: Threshold Increases of 1000: Money Values in Millions

\begin{tabular}{|c|c|c|c|c|c|}
\hline & Couples & $\begin{array}{r}\text { Single } \\
\text { men } \\
\end{array}$ & $\begin{array}{r}\text { Single } \\
\text { women }\end{array}$ & $\begin{array}{r}\text { Sole } \\
\text { parents }\end{array}$ & All \\
\hline \multicolumn{6}{|l|}{ Increase 2nd threshold } \\
\hline Net government revenue change (LS fixed) & -112.28 & -24.15 & -24.30 & -4.07 & -164.80 \\
\hline Net government revenue change (incl. LS) & -107.49 & -23.23 & -20.05 & 1.58 & -149.19 \\
\hline Average hours change in hours per week & $0.00,0.01$ & 0.00 & 0.02 & 0.08 & 0.01 \\
\hline Equivalent variation & -112.29 & -24.15 & -24.32 & -4.09 & -164.85 \\
\hline Marginal Welfare Cost & -0.04 & -0.04 & -0.21 & - & -0.10 \\
\hline Aggregate net income change & 122.94 & 25.21 & 26.81 & 8.01 & 182.97 \\
\hline Diff b/w net income change and EV (\%) & 8.66 & 4.23 & 9.30 & 48.90 & 9.91 \\
\hline \multicolumn{6}{|l|}{ Increase 3rd threshold } \\
\hline Net government revenue change (LS fixed) & -85.30 & -12.02 & -9.67 & -2.56 & -109.54 \\
\hline Net government revenue change (incl. LS) & & -10.86 & -9.33 & -2.08 & -104.50 \\
\hline Average hours change in hours per week & $0.00,0.01$ & 0.01 & 0.01 & 0.01 & 0.00 \\
\hline Equivalent variation & -85.32 & -12.02 & -9.68 & -2.56 & -109.59 \\
\hline Marginal Welfare Cost & -0.04 & -0.11 & -0.04 & -0.23 & -0.05 \\
\hline Aggregate net income change & 92.38 & 14.00 & 11.24 & 2.93 & 120.54 \\
\hline Diff b/w net income change and EV (\%) & 7.64 & 14.09 & 13.84 & 12.49 & 9.09 \\
\hline \multicolumn{6}{|l|}{ Increase 4th threshold } \\
\hline Net government revenue change (LS fixed) & -9.65 & -1.26 & -1.08 & -0.25 & -12.24 \\
\hline Net government revenue change (incl. LS) & -9.08 & -1.24 & -0.86 & -0.21 & -11.39 \\
\hline Average hours change in hours per week & $0.00,0.00$ & 0.00 & 0.00 & 0.00 & 0.00 \\
\hline Equivalent variation & -9.65 & -1.26 & -1.08 & -0.25 & -12.24 \\
\hline Marginal Welfare Cost & -0.06 & -0.02 & -0.25 & -0.22 & -0.08 \\
\hline Aggregate net income change & 10.78 & 1.33 & 1.51 & 0.20 & 13.82 \\
\hline Diff b/w net income change and EV (\%) & 10.52 & 5.00 & 28.55 & -27.16 & 11.41 \\
\hline
\end{tabular}

Note: The first 2 rows show the change in tax revenue net of changes in social transfer payments (in millions) with labour supply held fixed (row 1) and allowed to vary (row 2). Row 3 shows mean hours changes in labour supply: for couples, the first amount relates to the male partner while the second amount is for the female partner. Rows 4 and 5 report the equivalent variation (EV) and marginal welfare cost. Changes in aggregate net (after tax and transfers) incomes are shown in row 6, in millions, for the variable labour supply case. Row 7 gives the percentage difference between the EV and net income change. 
Table 6: Threshold Decreases of 1000: Money Values in Millions

\begin{tabular}{|c|c|c|c|c|c|}
\hline & Couples & $\begin{array}{r}\text { Single } \\
\text { men }\end{array}$ & $\begin{array}{c}\text { Single } \\
\text { women }\end{array}$ & $\begin{array}{c}\text { Sole } \\
\text { parents }\end{array}$ & All \\
\hline \multicolumn{6}{|l|}{ Decrease 2nd threshold } \\
\hline Net government revenue change (LS fixed) & 114.25 & 24.45 & 24.47 & 4.04 & 167.21 \\
\hline Net government revenue change (incl. LS) & 107.33 & 23.84 & 19.57 & 1.58 & 152.32 \\
\hline Average hours change in hours per week & $-0.01,-0.01$ & 0.00 & -0.02 & -0.03 & -0.01 \\
\hline Equivalent variation & 114.23 & 24.45 & 24.46 & 4.04 & 167.17 \\
\hline Marginal Welfare Cost & 0.06 & 0.03 & 0.25 & 1.55 & 0.10 \\
\hline Aggregate net income change & -122.41 & -25.15 & -26.70 & -5.38 & -179.65 \\
\hline Diff b/w net income change and EV (\%) & 6.68 & 2.79 & 8.41 & 25.00 & 6.94 \\
\hline \multicolumn{6}{|l|}{ Decrease 3rd threshold } \\
\hline Net government revenue change (LS fixed) & 88.46 & 12.34 & 10.13 & 2.67 & 113.60 \\
\hline Net government revenue change (incl. LS) & 78.31 & 11.44 & 9.00 & 1.22 & 99.98 \\
\hline Average hours change in hours per week & $-0.01,-0.01$ & 0.00 & -0.01 & -0.01 & -0.01 \\
\hline Equivalent variation & 88.42 & 12.34 & 10.12 & 2.66 & 113.54 \\
\hline Marginal Welfare Cost & 0.13 & 0.08 & 0.12 & 1.18 & 0.14 \\
\hline Aggregate net income change & -104.75 & -13.91 & -11.77 & -3.42 & -133.86 \\
\hline Diff b/w net income change and EV (\%) & 15.59 & 11.33 & 14.08 & 22.23 & 15.18 \\
\hline \multicolumn{6}{|l|}{ Decrease 4th threshold } \\
\hline Net government revenue change (LS fixed) & 10.13 & 1.35 & 1.15 & 0.27 & 12.90 \\
\hline Net government revenue change (incl. LS) & 8.94 & 1.29 & 0.90 & 0.33 & 11.47 \\
\hline Average hours change in hours per week & $0.00,0.00$ & 0.00 & 0.00 & 0.00 & 0.00 \\
\hline Equivalent variation & 10.13 & 1.35 & 1.15 & 0.27 & 12.89 \\
\hline Marginal Welfare Cost & 0.13 & 0.04 & 0.28 & -0.19 & 0.12 \\
\hline Aggregate net income change & -11.73 & -1.46 & -1.65 & -0.11 & -14.95 \\
\hline Diff b/w net income change and EV (\%) & 13.67 & 7.38 & 30.36 & -135.85 & 13.77 \\
\hline
\end{tabular}

Note: The first 2 rows show the change in tax revenue net of changes in social transfer payments (in millions) with labour supply held fixed (row 1) and allowed to vary (row 2). Row 3 shows mean hours changes in labour supply: for couples, the first amount relates to the male partner while the second amount is for the female partner. Rows 4 and 5 report the equivalent variation (EV) and marginal welfare cost. Changes in aggregate net (after tax and transfers) incomes are shown in row 6, in millions, for the variable labour supply case. Row 7 gives the percentage difference between the EV and net income change. 
leisure and home production time.

It is clear that changes in welfare and net income resulting from the small tax rate and threshold reforms considered can be quite different; these differences again ranging from around 7 to 14 per cent. For example, an increase in $t_{3}$ is associated with a 12.72 per cent smaller welfare reduction compared to the fall in aggregate net incomes. The equivalent value for a reduction in $t_{3}$ is a 7.95 per cent smaller increase in welfare. Overall however, increases and decreases in tax rates have fairly symmetric effects on aggregate welfare and average hours worked.

Table 7: Behavioural Revenue Responses as Percentage of Mechanical Changes

\begin{tabular}{|c|c|c|c|c|c|c|}
\hline & & & mograp & ic group & & \\
\hline & hange & Couples & $\begin{array}{l}\text { Single } \\
\text { men }\end{array}$ & $\begin{array}{l}\text { Single } \\
\text { women }\end{array}$ & $\begin{array}{l}\text { Sole } \\
\text { parents }\end{array}$ & Total \\
\hline & & & & & & \\
\hline$t_{1}$ & Increase & -7.5 & -2.2 & -22.8 & -69.7 & -10.3 \\
\hline & Decrease & 4.1 & 2.4 & 16.5 & 102.3 & 7.8 \\
\hline$t_{2}$ & Increase & -9.8 & -2.7 & -26.9 & -70.9 & -12.6 \\
\hline & Decrease & 6.0 & 4.9 & 17.9 & 77.5 & 9.4 \\
\hline$t_{3}$ & Increase & -9.7 & -6.7 & -13.7 & -35.9 & -10.3 \\
\hline & Decrease & 3.1 & 4.6 & 9.4 & 38.2 & 4.6 \\
\hline$t_{4}$ & Increase & -6.8 & -3.6 & -18.6 & 15.5 & -6.7 \\
\hline & Decrease & 8.6 & 2.8 & 12.3 & 23.8 & 8.2 \\
\hline & & & & & & \\
\hline$a_{2}$ & Decrease & -6.1 & -2.5 & -20.0 & -60.9 & -8.9 \\
\hline & Increase & 4.3 & 3.8 & 17.5 & 138.8 & 9.5 \\
\hline$a_{3}$ & Decrease & -11.5 & -7.3 & -11.2 & -54.3 & -12.0 \\
\hline & increase & 3.6 & 9.7 & 3.5 & 18.8 & 4.6 \\
\hline$a_{4}$ & decrease & -11.7 & -4.4 & -21.7 & 22.2 & -11.1 \\
\hline & Increase & 5.9 & 1.6 & 20.4 & 16.0 & 6.9 \\
\hline
\end{tabular}

The effects on net revenue of allowing for labour supply responses are shown by the differences between the first and second rows of each block of the tables. These can be quite substantial, with this 'behavioural effect' on total revenue ranging from 5 to 13 per cent of the estimated 'mechanical effect', which holds labour supply fixed. Table 7 summarises these behavioural revenue responses in total and across population sub-groups. The values shown are the percentage differences in the revenues given in Tables 3, 4, 5 and 6 .

For example, the decrease in total revenue due to labour supply responses to an increase in the 1st tax rate is equivalent to (minus) 10.3 per cent of the mechanical revenue increase. Revenue effects are largest for increases in $t_{2}$ both in absolute amounts and in terms of per- 
centage behavioural effects, shown in Table 7. Behavioural responses are also relatively large for decreases in the 3rd tax threshold, suggesting that the responsiveness of the relatively dense part of the income distribution facing $t_{2}$ below the $\$ 48,000$ threshold is especially important overall.

The contribution of the four household types to the behavioural revenue responses can also be seen to vary considerably, though the values for sole parents should be treated with caution since they are based on less than 10 per cent of total sample households and a much smaller fraction of total revenue changes. Nevertheless, it is clear that one of the consequences of the larger labour supply responses generally observed for single women is that their behavioural revenue responses are also relatively high, compared for example with those of single men.

\section{Changes to Marginal Tax Rates}

\subsection{Changes in Welfare per Dollar of Revenue}

Table 8 shows the resulting absolute values of the changes in welfare per dollar of revenue, $|\Delta W / \Delta R|$, for increases and decreases in each marginal tax rate by one percentage point. Results are shown using money metric utility and net income, for two values of the economies of scale parameter, $\alpha$, in the parametric adult equivalence scales, and three values of inequality aversion, $\varepsilon$. The weight attached to children, $\theta$, was set at 0.6 . In considering these values of $|\Delta W / \Delta R|$, it should be recognised that the revenue responses to tax changes arise only from labour supply changes. In practice, reported taxable income changes may be larger because of a range of other possible responses involving income shifting and under-reporting. ${ }^{13}$

The table indicates that marginal welfare gains and losses per dollar of revenue are not symmetric. For given values of $\varepsilon$ and $\alpha$, the welfare gains per dollar of revenue associated with a decrease in $t_{1}, t_{2}$ or $t_{3}$ are always smaller than the corresponding welfare losses associated with an increase in the same tax rate. The opposite result is found for $t_{4}$, with welfare gains from a tax rate reduction always larger than the welfare losses from a $t_{4}$ increase. The results shown in Tables 3 to 6 suggest that aggregate $E V$ values are approximately symmetric, along with changes in net government revenue. These results contrast with those for Australia reported in Creedy and Hérault (2012) who found that EV

\footnotetext{
${ }^{13}$ Other changes are included in responses described by the concept of the elasticity of taxable income (ETI). An extended version of this paper, Creedy et al. (2018), examines how far $|\Delta W / \Delta R|$ results based only on labour supply changes for top rate taxpayers can be extended to incorporate taxable income responses.
} 
and inequality changes were roughly symmetric but that revenue changes were asymmetric.

Table 8: Values of $\left|\frac{\Delta W}{\Delta R}\right|$ Using Money Metric Utility and Net Income

\begin{tabular}{|c|c|c|c|c|c|c|c|c|}
\hline & \multicolumn{4}{|c|}{ Increase in $t$} & \multicolumn{4}{|c|}{ Reduction in $t$} \\
\hline & $\varepsilon=0.1$ & $\varepsilon=0.2$ & $\varepsilon=0.8$ & $\varepsilon=1.4$ & $\varepsilon=0.1$ & $\varepsilon=0.2$ & $\varepsilon=0.8$ & $\varepsilon=1.4$ \\
\hline \multicolumn{9}{|c|}{ Money metric utility } \\
\hline \multicolumn{9}{|c|}{ Scale parameter: $\alpha=0.8$} \\
\hline$\overline{t_{1}}$ & 1.369 & 1.379 & 1.371 & 1.570 & 1.333 & 1.342 & 1.332 & 1.521 \\
\hline$t_{2}$ & 1.397 & 1.367 & 1.091 & 0.850 & 1.349 & 1.319 & 1.052 & 0.818 \\
\hline$t_{3}$ & 1.356 & 1.290 & 0.855 & 0.537 & 1.276 & 1.214 & 0.805 & 0.504 \\
\hline$t_{4}$ & 1.262 & 1.153 & 0.614 & 0.319 & 1.284 & 1.173 & 0.623 & 0.322 \\
\hline \multicolumn{9}{|c|}{ Scale parameter: $\alpha=0.4$} \\
\hline$t_{1}$ & 1.806 & 1.820 & 1.817 & 2.094 & 1.758 & 1.772 & 1.766 & 2.028 \\
\hline$t_{2}$ & 1.877 & 1.837 & 1.458 & 1.097 & 1.812 & 1.773 & 1.406 & 1.056 \\
\hline$t_{3}$ & 1.865 & 1.772 & 1.153 & 0.676 & 1.755 & 1.668 & 1.084 & 0.635 \\
\hline$t_{4}$ & 1.745 & 1.594 & 0.829 & 0.399 & 1.776 & 1.621 & 0.841 & 0.404 \\
\hline \multicolumn{9}{|c|}{ Net income } \\
\hline \multicolumn{9}{|c|}{ Scale parameter: $\alpha=0.8$} \\
\hline$t_{1}$ & 1.496 & 1.491 & 1.369 & 1.401 & 1.442 & 1.437 & 1.316 & 1.343 \\
\hline$t_{2}$ & 1.625 & 1.590 & 1.289 & 1.075 & 1.553 & 1.519 & 1.227 & 1.020 \\
\hline$t_{3}$ & 1.550 & 1.475 & 1.012 & 0.713 & 1.378 & 1.308 & 0.880 & 0.604 \\
\hline$t_{4}$ & 1.361 & 1.236 & 0.658 & 0.376 & 1.463 & 1.323 & 0.684 & 0.376 \\
\hline \multicolumn{9}{|c|}{ Scale parameter: $\alpha=0.4$} \\
\hline$t_{1}$ & 1.977 & 1.972 & 1.817 & 1.861 & 1.907 & 1.899 & 1.745 & 1.788 \\
\hline$t_{2}$ & 2.184 & 2.137 & 1.721 & 1.393 & 2.105 & 2.037 & 1.637 & 1.325 \\
\hline$t_{3}$ & 2.127 & 2.024 & 1.362 & 0.903 & 1.935 & 1.790 & 1.184 & 0.767 \\
\hline$t_{4}$ & 1.886 & 1.710 & 0.889 & 0.472 & 2.122 & 1.823 & 0.923 & 0.472 \\
\hline
\end{tabular}

As mentioned above, the direction of welfare-increasing changes to the tax parameters can be obtained by considering welfare changes per dollar, for reductions and increases in tax rates. However, it is important to examine adjustments to the tax system that keep total tax revenue unchanged, by combining an increase in one tax rate to fund a decrease in another tax rate. Such adjustments are of particular interest because they contribute to a welfare-improving change, at no cost for the government. The reform that keeps total tax revenue unchanged is the one involving an increase in the tax rate with the lowest welfare cost per extra dollar of revenue, combined with a decrease in the tax rate with the highest welfare gain per dollar of reduced revenue.

These are effectively revenue neutral changes, since they both consider changes per dollar of revenue. Nevertheless, the rule stated above (combing the lowest welfare cost per dollar when increasing revenue with the highest welfare gain per dollar when reducing rev- 
enue) does not give precise combinations of tax parameter changes which achieve revenue neutrality.

In the case of money metric utility, consider the welfare gains and losses for the lowest inequality aversion parameter of $\varepsilon=0.1$, along with the use of $\alpha=0.8$ for the scale economy parameter in the adult equivalence scales. This suggests that a revenue neutral reform that increases the social welfare function could be achieved by raising $t_{4}$ and reducing $t_{2}$. For aversion parameters of $\varepsilon=0.2$ and higher, the results suggest raising $t_{4}$ while simultaneously lowering $t_{1}$. These results are modified slightly with $\alpha=0.4$. In this case the rise in the top marginal rate is accompanied by lowering $t_{1}$ for values of $\varepsilon=0.8$ and higher.

These results contrast with those obtained for Australia, reported by Creedy and Hérault (2012), which generally suggested that a flattening of the rate structure would increase the social welfare function. The Australian income tax displays considerably more rate progression than in New Zealand, including a much higher top marginal rate of 0.47 (in the Creedy and Hérault study). ${ }^{14}$

In the case of net income as the welfare metric, consider the case where $\varepsilon=0.1$, and $\alpha=0.4$. Here, the largest changes in welfare per dollar of revenue are associated with upward and downward movements in $t_{4}$. In cases where the same rate is associated with, say, both the lowest $|\Delta W / \Delta R|$ for a rate increase and the highest $|\Delta W / \Delta R|$ for a rate reduction, the rule used above is insufficient. It is appropriate to use a more general rule: that the welfare-improving revenue-neutral change to the tax system is the one involving the largest difference between the welfare cost of the tax increase and the welfare gain of the tax decrease. In this case the best welfare-improving change involves an increase in $t_{4}$ combined with a reduction in $t_{2}$. The same result follows for $\varepsilon=0.2$, but for $\varepsilon=0.8$ and higher, the largest gain per dollar from a rate reduction is for $t_{1}$.

If the evaluation function reflects a complete absence of inequality aversion, $\varepsilon=0$, the value of the abbreviated social welfare function is simply the arithmetic mean money metric utility (or net income) per adult equivalent person. Setting $\varepsilon=0$, it is found in all cases (that is, for both money metric utility and net income, and for the two values of $\alpha$ considered) that the best welfare-improving reform involves a flattening of the tax rate structure, that is a reduction in the top marginal rate and an increase in the bottom rate. Hence, a small degree of aversion is sufficient to change the policy substantially. ${ }^{15}$

\footnotetext{
${ }^{14}$ However, it is important to distinguish rate progression from progressivity. The former refers to the schedule of marginal tax rates, whereas the latter refers to the extent of redistribution arising from the structure and depends on a wide range of further considerations.

${ }^{15} \mathrm{~A}$ zero aversion is of course consistent with a redistributive tax and transfer policy on 'efficiency' grounds, but it does not necessarily imply rate progression (that is, increasing marginal rates).
} 
It is important to stress that the results refer only to 'small' changes in tax rates and the direction of change; they can give no indication of the extent to which rates should be changed. Furthermore, it would not be appropriate to carry out simulations for larger tax rate changes. It would be possible for a large change in a marginal tax rate to move into the range where total revenue is decreasing, but where the change in revenue is nevertheless positive. That is, the movement could be from a point on the revenue-increasing side of the Laffer curve to a point on the revenue-reducing side, with an increase in total revenue arising from the large discrete change in the rate.

\subsection{Inequality Changes}

To assess the impacts of the alternative tax rate reforms on inequality, the top panel of Table 9 reports percentage changes in Atkinson inequality measures of money metric utility and net income for increases and decreases in the marginal income tax rates. In the case of money metric utility, pre-reform values of the Atkinson index are 0.0224, 0.0498, 0.2355 and 0.3276 for $\varepsilon=0.1,0.2,0.8$, and 1.4 respectively. The corresponding values for net income are $0.0115,0.0324,0.1863$ and 0.2298 . The table shows that inequality changes are approximately symmetric for tax rate increases and decreases.

In considering inequality changes, lowering $t_{1}$ gives the largest percentage reduction in inequality while, for rate increases, raising $t_{4}$ gives the largest percentage reduction. The introduction of more rate progression therefore unambiguously reduces the inequality of money metric utility. However the size of the inequality changes in Table 9 are very small in all cases. For example, the largest change is just over one-quarter of a per cent, for an increase in $t_{1}(\varepsilon=1.4 ; \alpha=0.8)$. This partly reflects the small size of the reform simulation.

Evaluation of the inequality effects of income tax reforms in practice is more often conducted in term of pre- and post-reform net incomes. It is therefore interesting to compare inequality outcomes from reform for money metric utility with those based on net incomes in the lower panel of the table. As with money metric utility, these are generally symmetric between tax rate increases and decreases and similar for $\alpha=0.8$ and $\alpha=0.4$.

Consider, for example, outcomes for the case of the one percentage point increase in the top marginal rate, $t_{4}$, for the alternative values of $\varepsilon$ and $\alpha$. This reveals that the apparent reductions in inequality (at all values of $\varepsilon$ and $\alpha$ ) when using net income as a basis for measurement are up to six times greater than when these are based on money metric utility. This is to be expected since any reductions in net incomes, associated with reduced labour supply resulting from the tax increase, exaggerate the decline in inequality as leisure or home production are not suitably valued. However, it serves to highlight that 
Table 9: Percentage Change in Atkinson's Index: Money Metric Uility and Net Income

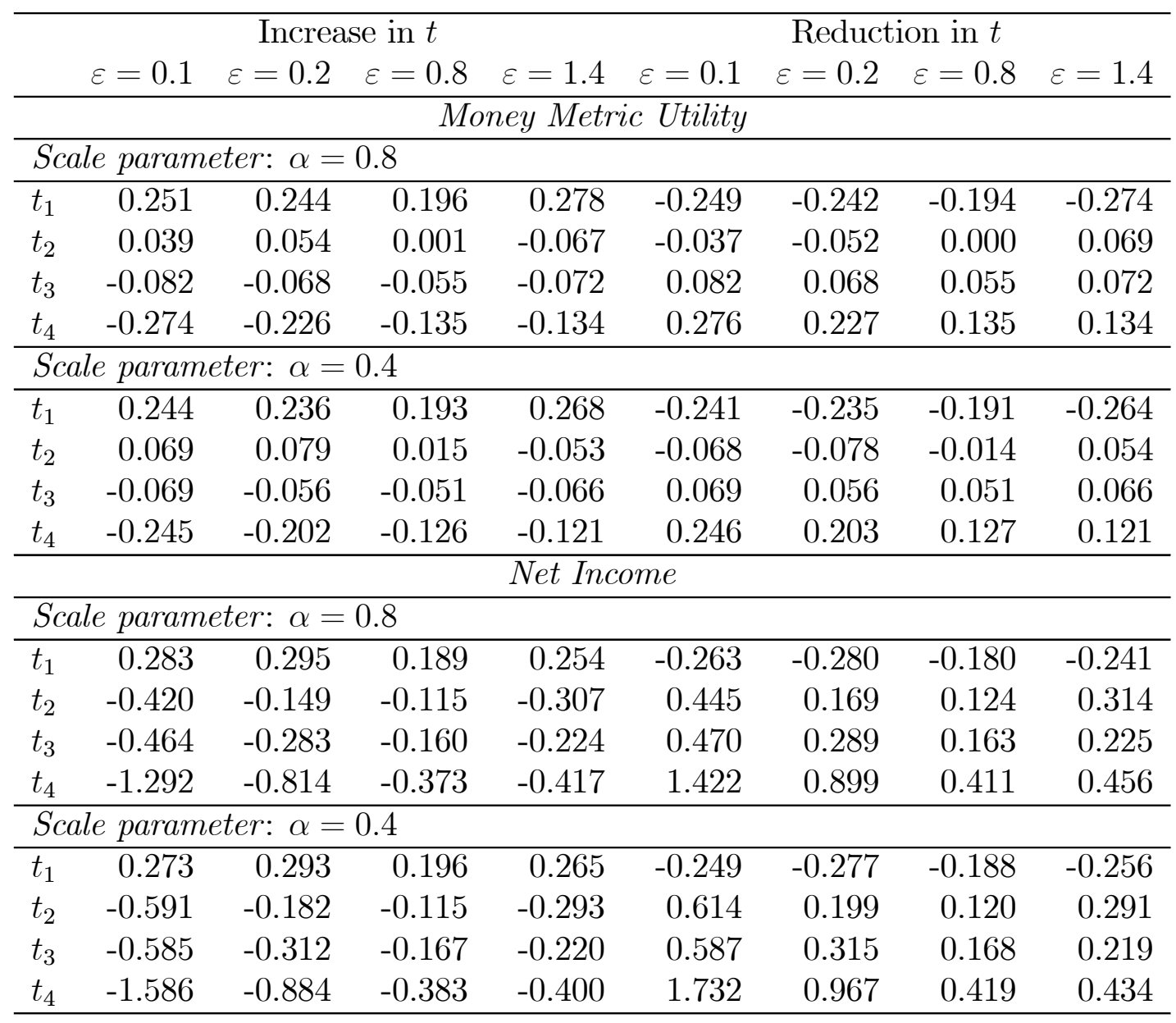


commonly quoted income-based inequality statistics may be quite inaccurate as a measure of the inequality impact of tax reforms on a broader measure of utility.

A similar difference can be seen to apply to the measured inequality impacts of changes in $t_{2}$ and $t_{3}$, while the metric used makes little difference to inequality changes resulting from changes in $t_{1}$. This latter result would suggest that the main inequality impact of changes in the marginal tax rate applicable below $\$ 14,000$ is not primarily related to labour supply decisions and resulting net income/leisure substitutions. This is perhaps less surprising when it is recognised that, for many such very low income taxpayers, $t_{1}(=0.105)$ is very different from applicable effective average and marginal rates given the array of tax credits and social benefits with associated abatement rates at such low income levels.

\section{Changes to Income Thresholds}

The previous discussion has concentrated on adjustments to income tax rates. However, it is of interest to consider the effects of changes in income thresholds. Clearly, any changes in tax thresholds which do not move an individual into a different tax bracket do not affect the marginal rate faced, but there is a change in net income if the threshold is below gross income (since a portion of lower income is taxed at a different rate). Individuals who are moved across thresholds experience changes in both marginal and average rates (at the pre-change gross income level). This section considers the welfare and inequality effects of threshold changes, along with the combination of rate and threshold changes.

\subsection{Welfare Effects per Dollar of Revenue Change}

Table 10 presents absolute values of marginal welfare changes per dollar of revenue, resulting from changes of $\$ 1000$ to the income thresholds in the tax schedule, again using values of $\alpha$ of 0.8 and 0.4 for the adult equivalence scale parameter (along with $\theta=0.6$ ). The lowest threshold, $a_{1}=0$, as there is no tax-free range, and marginal changes are not considered in this case.

In the case of threshold changes, it is necessary to look for the highest value of $\left|\frac{\Delta W}{\Delta R}\right|$ when thresholds are increased, since this involves welfare gains as some people are moved into a lower-rate bracket. When thresholds are reduced, this involves welfare losses as some people are moved into a higher-rate tax bracket, so it is necessary to look for the lowest value of $\left|\frac{\Delta W}{\Delta R}\right|$. Using money metric utility (shown in the top half of the table), when $\alpha=0.8$, the low $\varepsilon=0.1$ implies raising $a_{4}$ and reducing $a_{2}$. For $\varepsilon=0.2$ and higher, the preferred policy is to raise $a_{2}$ and reduce $a_{4}$. These outcomes are unchanged for the higher extent 
of economies of scale, $\alpha=0.4$. Higher inequality aversion therefore implies moving more people into the top-rate bracket, and more people into the bottom tax bracket. Only the lower aversion parameter of 0.1 implies moving some people out of the top tax bracket. ${ }^{16}$

Table 10: Values of $\left|\frac{\Delta W}{\Delta R}\right|$ for Income Threshold Changes

\begin{tabular}{|c|c|c|c|c|c|c|c|c|}
\hline & \multicolumn{4}{|c|}{ Increase } & \multicolumn{4}{|c|}{ Decrease } \\
\hline & $\varepsilon=0.1$ & $\varepsilon=0.2$ & $\varepsilon=0.8$ & $\varepsilon=1.4$ & $\varepsilon=0.1$ & $\varepsilon=0.2$ & $\varepsilon=0.8$ & $\varepsilon=1.4$ \\
\hline \multicolumn{9}{|c|}{ Money Metric Utility } \\
\hline \multicolumn{9}{|c|}{ Scale parameter: $\alpha=0.8$} \\
\hline$a_{2}$ & 1.353 & 1.357 & 1.287 & 1.229 & 1.344 & 1.349 & 1.287 & 1.240 \\
\hline$a_{3}$ & 1.283 & 1.230 & 0.852 & 0.559 & 1.390 & 1.334 & 0.931 & 0.616 \\
\hline$a_{4}$ & 1.403 & 1.226 & 0.946 & 0.679 & 1.360 & 1.284 & 0.814 & 0.488 \\
\hline \multicolumn{9}{|c|}{ Scale parameter: $\alpha=0.4$} \\
\hline$a_{2}$ & 1.784 & 1.792 & 1.708 & 1.610 & 1.773 & 1.782 & 1.709 & 1.624 \\
\hline$a_{3}$ & 1.762 & 1.687 & 1.147 & 0.706 & 1.908 & 1.829 & 1.254 & 0.778 \\
\hline$a_{4}$ & 1.918 & 1.690 & 1.271 & 0.865 & 1.879 & 1.768 & 1.099 & 0.612 \\
\hline \multicolumn{9}{|c|}{ Net Income } \\
\hline \multicolumn{9}{|c|}{ Scale parameter: $\alpha=0.8$} \\
\hline$a_{2}$ & 1.497 & 1.489 & 1.335 & 1.234 & 1.440 & 1.432 & 1.285 & 1.190 \\
\hline$a_{3}$ & 1.403 & 1.343 & 0.946 & 0.679 & 1.640 & 1.576 & 1.143 & 0.848 \\
\hline & 1.457 & 1.369 & 0.864 & 0.557 & 1.557 & 1.467 & 0.946 & 0.632 \\
\hline \multicolumn{9}{|c|}{ Scale parameter: $\alpha=0.4$} \\
\hline$a_{2}$ & 1.975 & 1.965 & 1.771 & 1.624 & 1.903 & 1.894 & 1.706 & 1.564 \\
\hline$a_{3}$ & 1.918 & 1.834 & 1.271 & 0.865 & 2.249 & 2.159 & 1.536 & 1.077 \\
\hline$a_{4}$ & 2.005 & 1.883 & 1.164 & 0.705 & 2.135 & 2.010 & 1.270 & 0.799 \\
\hline
\end{tabular}

When net income is used as the welfare metric, the implications again differ compared with the use of money metric utility. For the higher inequality aversions of 0.8 and 1.4, and $\alpha=0.8$, the smallest welfare loss per dollar of revenue arises from reducing the top income threshold, $a_{4}$, while the biggest gain arises from raising the threshold $a_{2}$. For $\varepsilon=0.1$ and 0.2 the smallest loss is from reducing $a_{2}$, while the biggest gain is also from raising $a_{2}$. This means, as with the use of net income when considering marginal rate changes, that it is necessary to examine the largest net gain from all combinations of threshold increases and reductions. In the case of $\varepsilon=0.1$, the only combination which gives a positive net gain is for raising $a_{4}$ while also lowering $a_{2}$. For $\varepsilon=0.2$, the only combination giving a positive net

\footnotetext{
${ }^{16}$ Instead of changing each threshold in turn, a policy of simultaneously raising all income thresholds by $\$ 1 \mathrm{k}$ was examined. In each case (that is, for both money metric utility and net income as the welfare metric, and each equivalent adult scale parameter) it was found that the welfare benefit per dollar of revenue reduction was not as high as when a single threshold was raised.
} 
gain involves raising $a_{2}$ combined with lowering $a_{4}$ : this corresponds to the policy arising from the higher inequality aversion parameters.

Table 11 reports the inequality changes as the thresholds are changed. The top half refers to money metric utility while the lower half reports results for net income. In each case, the values of inequality change are, unsurprisingly, very small due to the small change of $\$ 1,000$ in each threshold simulated. Also, comparable to the case of the tax rate reform simulations described above, changes in the lower threshold, $a_{2}$, are similar whether net income or money metric utility is used (especially at lower values of $\varepsilon$ ), while changes in higher thresholds, $a_{3}$ and $a_{4}$, are relatively larger when based on net incomes. For example, increasing $a_{3}$ by $\$ 1,000$ increases the Atkinson index by $0.296(0.180)$ per cent for $\varepsilon=0.1$ (0.2), and $\alpha=0.8$, based on net incomes, but by only 0.045 (0.036) based on money metric utility.

Table 11: Percentage Change in Atkinson's Index and Threshold Changes: Money Metric Utility and Net Income

\begin{tabular}{|c|c|c|c|c|c|c|c|c|}
\hline & \multicolumn{4}{|c|}{ Increase } & \multicolumn{4}{|c|}{ Reduction } \\
\hline & $\varepsilon=0.1$ & $\varepsilon=0.2$ & $\varepsilon=0.8$ & $\varepsilon=1.4$ & $\varepsilon=0.1$ & $\varepsilon=0.2$ & $\varepsilon=0.8$ & $\varepsilon=1.4$ \\
\hline \multicolumn{9}{|c|}{ Money Metric Utility } \\
\hline \multicolumn{9}{|c|}{ Scale parameter: $\alpha=0.8$} \\
\hline$a_{2}$ & -0.104 & -0.102 & -0.073 & -0.066 & 0.110 & 0.106 & 0.076 & 0.071 \\
\hline$a_{3}$ & 0.045 & 0.036 & 0.033 & 0.048 & -0.044 & -0.035 & -0.033 & -0.049 \\
\hline$a_{4}$ & 0.010 & 0.008 & 0.006 & 0.007 & -0.010 & -0.008 & -0.006 & -0.008 \\
\hline \multicolumn{9}{|c|}{ Scale parameter: $\alpha=0.4$} \\
\hline$\overline{a_{2}}$ & -0.104 & -0.101 & -0.074 & -0.064 & 0.109 & 0.105 & 0.077 & 0.069 \\
\hline$a_{3}$ & 0.036 & 0.028 & 0.031 & 0.044 & -0.035 & -0.027 & -0.030 & -0.045 \\
\hline$a_{4}$ & 0.009 & 0.007 & 0.006 & 0.007 & -0.008 & -0.007 & -0.006 & -0.007 \\
\hline \multicolumn{9}{|c|}{ Net Income } \\
\hline \multicolumn{9}{|c|}{ Scale parameter: $\alpha=0.8$} \\
\hline$\overline{a_{2}}$ & -0.105 & -0.120 & -0.070 & -0.040 & 0.104 & 0.117 & 0.067 & 0.039 \\
\hline$a_{3}$ & 0.296 & 0.180 & 0.110 & 0.160 & -0.289 & -0.168 & -0.101 & -0.154 \\
\hline$a_{4}$ & 0.055 & 0.030 & 0.020 & 0.020 & -0.056 & -0.035 & -0.019 & -0.024 \\
\hline \multicolumn{9}{|c|}{ Scale parameter: $\alpha=0.4$} \\
\hline$a_{2}$ & -0.103 & -0.121 & -0.074 & -0.046 & 0.099 & 0.119 & 0.072 & 0.045 \\
\hline$a_{3}$ & 0.377 & 0.197 & 0.109 & 0.152 & -0.376 & -0.190 & -0.107 & -0.155 \\
\hline$a_{4}$ & 0.068 & 0.037 & 0.019 & 0.023 & -0.068 & -0.038 & -0.019 & -0.024 \\
\hline
\end{tabular}


Table 12: Values of $\left|\frac{\Delta W}{\Delta R}\right|$ Using Money Metric Utility for Combinations of Rate and Threshold Changes

\begin{tabular}{lllll}
\hline$(\alpha=0.8)$ & Threshold & & Marginal rate \\
\hline$\varepsilon=0.1$ & & & & \\
Biggest gain & Raise $a_{4}:$ & 1.403 & Reduce $t_{2}:$ & 1.349 \\
Smallest loss & Reduce $a_{2}:$ & 1.344 & Raise $t_{4}:$ & 1.262 \\
\hline$\varepsilon=0.2$ & & & & \\
Biggest gain & Raise $a_{2}:$ & 1.357 & Reduce $t_{1}: 1.342$ \\
Smallest loss & Reduce $a_{4}: 1.284$ & Raise $t_{4}:$ & 1.153 \\
\hline
\end{tabular}

\subsection{Rate and Threshold Changes Combined}

Using the information provided in Tables 8 and 10, it is possible to extract combinations of rate and threshold changes that give rise to the largest welfare gains per dollar of revenue (for rate reductions and threshold increases) and the smallest welfare losses (for rate increases and threshold reductions). These are shown in Table 12 for the case where $\alpha=0.8$. Hence, for the lower inequality aversion of $\varepsilon=0.1$, the biggest gain arises from raising the income threshold, $a_{4}$, and combining this with the smallest loss, obtained by raising the top marginal rate, $t_{4}$. This means that some people would be moved out of the top tax bracket into a lower-tax bracket, while those remaining in the top bracket would face a higher rate. By contrast, for higher inequality aversion of $\varepsilon=0.2$, the biggest welfare improvement arises from combining a rise in the threshold, $a_{2}$, (giving the biggest gain) with a rise in the top rate, $t_{4}$ (giving the smallest loss). Inequality aversion therefore influences the choice of group to be shifted to a lower-tax bracket.

\section{Conclusions}

This paper began by questioning whether welfare-improving marginal changes to the structure of the income tax in New Zealand might involve increased tax rate progression, with a higher top marginal rate, or a flattening of the rate structure as suggested by results for Australia. The paper examined welfare-improving reforms using a behavioural tax microsimulation model and a range of assumptions concerning the social welfare, or evaluation, function. In looking for practical advice regarding marginal adjustments to tax parameters, behavioural microsimulation can provide the kind of detail needed, and captures the considerable complexity of actual tax-transfer systems and the large degree of population heterogeneity found in practice.

Welfare changes per dollar of revenue were obtained using additive Paretian welfare 
functions displaying constant relative inequality aversion. Two alternative welfare metrics were used in the social welfare function. One, for 'welfarist' functions, involves the use of money metric utility per adult equivalent person. The 'non-welfarist' alternative of net income, commonly used for tax policy advice in practice, was also investigated and compared.

It was found that, for a wide range of inequality aversion parameters used for the welfare function, and for different scale economies in adult equivalence parameters, reforms involved increasing the top rate of income tax, and reducing lower rates. It was shown how to combine these changes in a revenue neutral way. Additionally, larger welfare improvements were obtained when changes in income tax rates and thresholds are combined. The model also produced estimates of the behavioural component of revenue changes associated with the reforms simulated. In aggregate, these were shown to vary from around five to fourteen per cent of the mechanical revenue effects of reform, and with substantially larger variation across household types.

Identifying welfare improving directions of reform as involving an increase in the degree of marginal rate progression contrasts with results from a similar microsimulation exercise for Australia. However, with a top marginal rate in New Zealand much lower than in Australia, these results may be consistent with welfare improving directions for reform in each country. Further, results for both countries were obtained from models in which labour supply adjustments are the only behavioural responses. Drawing on the literature on the elasticity of taxable income, which accounts for additional income responses such as tax evasion or avoidance and bargaining over salaries, we found in an extended version of this paper, Creedy et al. (2018), that these additional responses would have to be particularly large in this case to qualitatively alter results for the top marginal rate.

Finally, making welfare comparisons based on money metric utility rather than net income was shown to be potentially important for policy reform conclusions. For example, the inequality impacts of tax rate changes can appear to be much larger when net income rather than utility is used, highlighting the importance of recognising and calibrating the social welfare impact of changes in leisure time in the evaluation of alternative tax or transfer reforms. 


\section{References}

[1] Aaberge, R. and Colombino, U. (2008) Designing optimal taxes with a microeconometric model of household labour supply. Centre for Household Income, Labour and Demographic Economics Working Paper 06/2008

[2] Ahmad, E. and Stern, N. (1984) The theory of reform and Indian indirect taxes. Journal of Public Economics, 25, 259-298.

[3] Amiel, Y., Creedy, J. and Hurn, S. (1999) Measuring attitudes towards inequality. Scandinavian Journal of Economics, 101, 83-96.

[4] Banks, J. and Johnson, P. (1994) Equivalence scale relativities revisited. Economic Journal, 104, 883-890.

[5] Besley, T. and Coate, S. (1992) Workfare versus welfare: incentive arguments for work requirements in poverty-alleviation programs. American Economic Review, 249-261.

[6] Blackorby, C., Laisney, F. and Schmachtenberg, R. (1993) Reference-price-independent welfare prescriptions. Journal of Public Economics, 50, 63-76.

[7] Blundell, R. and Shephard, A. (2009) Employment, hours of work and the optimal taxation of low income families. Institute for Fiscal Studies Working Paper, WP08/01.

[8] Bourguignon, F., Fournier, M. and Gurgand, M. (2001) Fast development with a stable income distribution: Taiwan, 1979-94. Review of Income and Wealth, 47, 139-163.

[9] Capéau, B., Decoster, A. and Dekkers, G. (2016) Estimating and simulating with a random utility random opportunity model of job choice. Presentation and application to Belgium. International Journal of Microsimulation, 9, 144 - 191.

[10] Creedy, J. and Hérault, N. (2012) Welfare-improving income tax reforms: a microsimulation analysis. Oxford Economic Papers, 64, 128-150.

[11] Creedy, J., Hérault, N. and Kalb, G. (2011) Measuring welfare changes in behavioural microsimulation modelling: accounting for the random utility component. Journal of Applied Economics, 14, 5-34.

[12] Creedy, J. and Kalb, G. (2005) Measuring welfare changes in labour supply models. Manchester School, 73, 664-685. 
[13] Creedy, J. and Kalb, G. (2006) Labour Supply and Microsimulation: The Evaluation of Tax Policy Reforms. Cheltenham: Edward Elgar.

[14] Creedy, J., Kalb, G. and Scutella, R. (2006) Income distribution in discrete hours behavioural microsimulation models: an illustration. Journal of Economic Inequality, $4,57-76$.

[15] Creedy, J. and Mok, P. (2018) The marginal welfare cost of personal income taxation in New Zealand. New Zealand Economic Papers. 52, 323-338.

[16] Dagsvik, J.K. and Karlström, A. (2005) Compensating variation and Hicksian choice probabilities in random utility models that are nonlinear in income. Review of Economic Studies, 72, 57-76.

[17] Dagsvik, J.K., Jia, Z., Kornstad, T. and Thoresen, T.O. (2014). Theoretical and practical arguments for modeling labor supply as a choice among latent jobs. Journal of Economic Surveys, 28, 134-151.

[18] Decoster, A. and Haan, P. (2015) Empirical welfare analysis with preference heterogeneity. International Tax and Public Finance, 22, 224 - 251.

[19] Donaldson, D. (1992) On the aggregation of money measures of well-being in applied welfare economics. Journal of Agricultural and Resource Economics, 17, 88-102.

[20] Ericson, P. and Flood, L. (2009) A microsimulation approach to an optimal Swedish income tax. IZA Discussion Paper no. 4379.

[21] Fleurbaey, M. and Maniquet, F. (1999) Optimal income taxation: an ordinal approach. THEMA Discussion Paper, 99-43.

[22] Hanemann, W.M. (1983), Marginal welfare measures for discrete choice models, Economics Letters, 13, 129-36.

[23] Jenkins, S.P. and Cowell, F.A. (1994) Parametric equivalence scales and scale relativities, Economic Journal, 104, 891-900.

[24] Lambert, P. (1993) The Distribution and Redistribution of Income: A Mathematical Treatment. Manchester: Manchester University Press.

[25] Mercante, J. and Mok, P. (2014a). Estimation of labour supply in New Zealand. New Zealand Treasury Working Paper, WP 14/08. 
[26] Mercante, J. and Mok, P. (2014b). Estimation of wage equations for New Zealand. New Zealand Treasury Working Paper, WP 14/09.

[27] Nolan, P. (2017) Family and Work Tax Credits in Five Liberal Welfare States. Presentation to the New Zealand Association of Economists Annual Conference, Victoria University of Wellington (July). Available at www.productivity.govt.nz/research. Accessed on 27 April 2018.

[28] Preston, I., and Walker, I. (1999) Welfare Measurement in labour supply models with nonlinear budget constraints. Journal of Population Economics, 12, 343-361.

[29] Tax Working Group (2018) Future of Tax. Submissions Background Paper. Wellington: New Zealand Government. Available at www.taxworkinggroup.govt.nz/key-documents. Accessed on 06 February 2019.

[30] Thoresen, T.O. (2004). Reduced tax progressivity in Norway in the Nineties. The effect from tax changes. International Tax and Public Finance, 11, 487-506.

[31] Thoresen, T.O. and Vattø, T.E. (2015) Validation of the discrete choice labor supply model by methods of the new tax responsiveness literature. Labor Economics, 37, 38-53. 